\title{
Pamuk Çiğidi Küspesi ve Kırmızı Biber İşleme Atıklarından Biyoyakıt Amaçlı Pelet Elde Edilmesi
}

\author{
Ülkü Fidan BAŞIBÜYÜK ${ }^{1}$ ORCID 0000-0002-8869-7329 \\ Ali AYBEK ${ }^{1}$ ORCID 0000-0002-3036-8204 \\ Serdar ÜÇOK ${ }^{* 1}$ ORCID 0000-0002-7158-669X
}

${ }^{1}$ Kahramanmaraş Sütçü İmam Üniversitesi, Ziraat Fakültesi, Biyosistem Mühendisliği Bölümü, Kahramanmaraş

Geliş tarihi: 19.02.2021 Kabul tarihi: 10.12.2021

Atıf şekli/ How to cite: BAŞIBÜYÜK, Ü.F., AYBEK, A., ÜÇOK, S., (2021). Pamuk Çiğidi Küspesi ve Kırmızı Biber İşleme Atıklarından Biyoyakıt Amaçlı Pelet Elde Edilmesi. Çukurova Üniversitesi, Mühendislik Fakültesi Dergisi, 36(4), 879-890.

$\ddot{\mathbf{O z}}$

Bu çalışmada, tekstil fabrikalarından alınan pamuk çiğidi küspesi (PÇK) ile biber fabrikalarından alınan kırmızı biber işleme atıklarından (KB) enerji üretim amaçlı pelet elde edilmesi amaçlanmıştır. Elde edilen peletlerin fiziksel ve kimyasal özellikleri ile beraber peletlerin mekanik özellikleri, 1sıl ve yanma özellikleri belirlenmiştir. Materyaller partikül boyutuna getirilip farklı oranlarda 5 farklı karışım (\%100 $\mathrm{PÇK}, \% 75 \mathrm{PCC}+\% 25 \mathrm{~KB}, \% 50 \mathrm{PÇK}+\% 50 \mathrm{~KB}, \% 25 \mathrm{PCC}+\% 75 \mathrm{~KB}$ ve \%100 KB) oluşturulmuştur. Karışımlar 6 kW motor gücüne sahip olan ve işleme kapasitesi 70-90 kg/h olan, dairesel sıralı delikli düz kalıplı laboratuvar tipi bir peletleme makinesi kullanılarak peletlenmiştir. Peletlerin kalitesi ile ilgili olarak pelet parça yoğunluğu 994,06-1177,51 kg/m³ , dikey basma gerilme direnci 165,01-319,82 N, nem alma oranı \%20,06-23,25 ve kırılma direnci \%99,04-99,71 değerleri arasında bulunmuştur. Peletlerin diğer özellikleri ise kül içeriği \%14,38-\%19,99, nem içeriği \%6,58-\%9,59, sabit karbon oranı \%13,57$\% 21,27$, uçucu madde içeriği ise \%54,74-\%61,86, toplam azot oranı \%3.80-\%5.56, toplam karbon oranı $\% 38,15-\% 41,71$, üst 1sıl değeri 13,01-\%15,18 MJ/kg aralığında belirlenmiştir. \%100 PÇK'den üretilen peletler; termogravimetrik analizler, nem alma oranı hesaplamaları ve dikey sıkıştırma analizi hesaplamaları neticesinde en iyi biyoyakıt olarak belirlenmiştir. Sonuç olarak kırmızı biber işleme atıkları ve pamuk çiğidi küspesinden enerji amaçlı pelet üretimi yapılabileceğini göstermiştir.

Anahtar Kelimeler: Biyokütle, Biyoyakıt, Pamuk çiğidi küspesi, Kırmızı biber işleme atıkları, Peletleme

\footnotetext{
*Sorumlu yazar (Corresponding author): Serdar ÜÇOK, sucok@ksu.edu.tr
} 


\title{
Pellet Production for Biofuel from Cotton Cake and Red Pepper Processing Wastes
}

\begin{abstract}
In this study, aimed to obtain pellets for energy production from cotton seed meal (CCP) from textile factories and red pepper processing wastes (RPPW) from pepper factories and Diameter, length, weight, pellet particle density, fracture resistance, vertical compression resistance, moisture uptake resistance, moisture content, ash content, volatile matter amounts, and thermogravimetric analysis were determined. There resulting mixtures are $100 \% \mathrm{CCP}, 75 \% \mathrm{CCP}+25 \% \mathrm{RPPW}, 50 \% \mathrm{CCP}+50 \% \mathrm{RPPW}, 25 \% \mathrm{CCP}$ $+75 \%$ RPPW and 100\% RPPW. The mixes obtained were pelleted using a circular row perforated flat die laboratory pelletizing machine with a $6 \mathrm{~kW}$ motor power and a processing capacity of $70-90 \mathrm{~kg} / \mathrm{h}$. Regarding the quality of the pellets, the pellet particle density was $994.06-1177.51 \mathrm{~kg} / \mathrm{m}^{3}$, the vertical compression strength was 165.01-319.82 N, the moisture uptake resistance was $20.06-23.25 \%$ and the fracture resistance was between $99.04-99.71 \%$. Ash content of pellets was $14.38 \%-19.99 \%$, moisture content was $6.58 \%-9.59 \%$, fixed carbon rate was $13.57 \%-21.27 \%$, volatile matter content was $54.74 \%$ $61.86 \%$, total nitrogen content was $3.80 \%-5.56 \%$, total carbon was $38.15 \%-41.71 \%$ and its higher heating value was $13.01 \%-15.18 \mathrm{MJ} / \mathrm{kg}$. Pellets produced from $100 \%$ PÇK was determined as the best biofuel as a result of thermogravimetric analysis, dehumidification rate calculations and vertical compression analysis calculations As a result, red pepper processing waste and cotton seed meal are suitable materials for energy pellet production.
\end{abstract}

Keywords: Biomass, Biofuel, Cotton seed meal, Red pepper processing waste, Pelleting

\section{GíRiş}

Dünyadaki nüfus artışı ve teknolojinin gelişimi neticesinde enerjiye olan gereksinim günden güne artmaktadır. Gelişmekte olan ve gelişmiş ülkelerde gerekli enerji ihtiyacının karşılanması için fosil yakıtlar kullanılmaktadır. Dünyada enerjiye olan ihtiyaç her yıl $\% 5$ oranında artmaktadır. $\mathrm{Bu}$ artış neticesinde fosil kaynaklı yakıtların miktarı da gün geçtikçe büyük oranda azalmaktadır. Bu durum yeni enerji kaynakları arayışlarını ortaya çıkarmıştır. $\mathrm{Bu}$ anlamda mevcut enerji kaynaklarına ek olarak son yıllarda yenilenebilir enerji kaynaklarına, özellikle biyokütle kaynaklarından enerji üretimi ile bu soruna alternatif çözümler aranmaktadır [1]. Biyokütle enerjisi, çevre ile dost sürdürülebilir enerji üretimini ve çevre yönetimini sağlayan, kalkınmayı hedefleyen özellikleri ile tüm dünyada geniş bir uygulama alanı bulmuştur. Bu bakımdan Türkiye'de de biyokütlenin, enerji üretiminde değerlendirilmesi konusu önem kazanmıştır [2]. Biyokütlenin kullanılması ile üretilen enerjinin kalkınmaya yardımcı olması ve Kyoto protokolünün amaçları ile uyuşması açısından oldukça önemlidir [3].
Biyokütlenin kullanılabilmesi için teknolojik sorunların giderilmesi gerekmektedir [4]. Tarımsal atıkların yüksek nem içeriğine sahip olmaları ve yoğunluklarının düşük olmaları nedeniyle evlerde ve endüstriyel alanlarda hiçbir işlem görmeden direkt olarak kullanılması hem çok etkili olmamakta hem de taşıma, depolama gibi aşamalarında ekonomik olmamaktadır. Bu sorunlar biyokütlenin peletlenmesi ile daha aza indirgenmektedir. Peletleme; dağınık halde olan biyokütlenin yüksek basınçla sıkıştırılarak taşıma ve depolama açısından daha kolay olan ve çevre dostu biyokütleye çevrilmesine denilmektedir [5].

Türkiye'de hem artan enerji ithal yükünün azaltılması, hem de enerji ve çevre sorununa sürdürülebilirlik ilkesi ile yaklaşılması açısından, önemli bir potansiyeli bulunan yeni ve yenilenebilir enerji kaynaklarının kullanılması önemlidir. Tarım ve tarıma dayalı sanayide önemli düzeyde biyokütle materyalleri mevcuttur. Bu materyaller biyoyakıt amaçlı pelet elde edilmesi için kullanılabilir. Materyallerin peletlenmesi ile hacimsel 1 sı değeri artar, taşıma ve depolama maliyetleri azalır, ısıl özellikleri iyileşir, atmosfere salınan parçacık emisyonları azalır ve aynı 
boyut/şekilde daha üstün özelliklere sahip bir biyoyakıt elde edilebilir. Bitkisel atıklardan enerji üretmek amaciyla etkin ve kolay bir şekilde kullanabilmek için uygulanacak yöntemlerden birisi de bu atıkların kurutulup, ögütüldükten sonra preslenerek pelet haline getirilmesidir [6].

Günümüzde Türkiye'de bazı sanayilerde tarımsal ve fabrika atıklarından büyük ölçekte yararlanılamamaktadır. Türkiye'de biyokütle enerjisi kullanımının önündeki ekonomik engeller ile politika ve piyasa araçlarının yetersizliği gibi nedenler sonucunda biyokütle ve katı atık işleten enerji tesislerinde özel sektör henüz yeterli düzeyde ilgi duymamaktadır. Tarımsal üretim neticesinde geriye kalan bitkisel artıkların herhangi bir yöntemle değerlendirilmeyip yok edilmesi ciddi düzeyde çevre kirliliğini beraberinde getirmekte ve ekonomik bir kayıp oluşturmaktadır. Ortaya çıkan çevre kirliliğinin ve ekonomik kayıpların önüne geçebilmek için atık sorunlarında peletleme yöntemi uygun bir yöntemdir [7].

Tarımsal ve tarıma dayalı sanayi atıkları, özelikle gelişmekte olan ülkelerde enerji ihtiyacının karşılanabilmesi için önemli bir kaynak oluşturmaktadır. Birçok gelişmiş ülkede katı atıklar, biyokütlenin peletlenmesi işlemi ile yararlı, kullanılabilir ve ekonomik ürünlere dönüştürülmektedir [8].

Peletleme yöntemi, dağınık haldeki biyokütlenin kurutulup öğütülmesinin ardından yüksek basınçta sıkıştırılması ile yapılmaktadır. Pelet üretiminde odun talaşı, zeytin küspesi, mısır koçanı, kırmızıbiber işleme atıkları, kiraz çekirdeği, pamuk çiğidi küspesi gibi atıklar kullanılabilmektedir. Elde edilen peletler, hacimsel olarak üretiminde kullanılan organik atıklardan daha az yer kaplamaktadır. Nem içeriği daha az olduğu için daha uzun süre depolanabilmekte ve daha fazla ısı açığa çıkarmaktadır. Bununla birlikte fosil kaynaklı yakıtlara göre daha ucuzdur. Üretilen peletlerin dayanıklılığının yüksek olması ve kullanıcıya sağlam bir şekilde ulaşması oldukça önemlidir. Dayanıklılığı yüksek olan peletlerin taşınması ve depolanması daha kolay olmaktadır [9].
Kahramanmaraş yöresi kırmızıbiber ve pamuk üretimi ile tanınan bir bölgedir. Kırmızıbiber işleme atıkları ile pamuk çiğidi küspesi kullanılarak enerji amaçlı pelet üretilmesi, yöreye, ülkeye ekonomik ve çevresel korunma açısından önemli katkılar sağlayabilecektir.

$\mathrm{Bu}$ çalışmanın temel amacı pamuk çiğidi küspesi ve kırmızıbiber işleme atıklarından biyoyakıt amaçlı pelet elde edilmesidir.

Spesifik amaçları ise;

- Peletlerin fiziksel ve kimyasal özelliklerini (Nem, uçucu madde, sabit karbon, C, H, N, kül, üst 1sil) belirlemek,

- Peletlerin mekanik özelliklerini (dayanıklılık, kırılma direnci, sıkıştırma direnci, nem alma direnci) belirlemek,

- Peletlerin yanma karakteristiklerini belirlemektir.

\section{2. ÖNCEKİ ÇALIŞMALAR}

Y1lmaz (2014), bazı tarımsal atıkların peletlenmesi ve pelet fiziksel özelliklerinin belirlenmesi üzerine yapılan çalışmada pamuk ve susam saplarının peletlenmesi işlemi amaçlanmıştır. Çalışmada, üç farklı nem içeriğine sahip olan kurutulup ögütülmüş haldeki pamuk ve susam sapları kullanılmıştır. Peletlerin sıkıștırma direnci, dayanıklılık direnci, gerilme direnci, kırılma direnci ve nem alma direnci belirlenmiştir. Çalışmanın sonucunda, elde edilen silindirik peletlerin çap aralığının $8,1 \mathrm{~mm}$ ile $8,97 \mathrm{~mm}$ arasında değiştiği belirlenmiştir. Ayrıca peletlerin nem içeriğinin arttıkça yoğunluklarının da arttığ1 belirlenmiş olup, hacim yoğunluğunun 430-717 $\mathrm{kg} / \mathrm{m}^{3}$, parça yoğunluğunun ise $922-1368 \mathrm{~kg} / \mathrm{m}^{3}$ değiştiği belirlenmiştir. Peletlerin, fiziksel testler sonucunda oldukça dayanıklı bir yapıya sahip olduğu belirlenmiştir [10].

Gürdil ve arkadaşları (2016), yaptıkları çalışmada findık zurufu atığını peletlemişlerdir. Fındık zurufu atıklarının öğütme inceliği $6 \mathrm{~mm}$ ve nem içeriği \%12 olarak belirlenmiştir. Materyalin geometrik ortalama çapı 1,64 mm olarak hesaplanmıştır. Peletleme işlemi düz kalıplı $15 \mathrm{~kW}$ gücünde olan pelet makinesinde yapılmıştır. 
Analizler sonucunda; pelet parça yoğunluğu $1309,87 \mathrm{~kg} / \mathrm{m}^{3}$, pelet dayanıklılık direnci $\% 89,57$, nem içeriği değeri \%11,54 olarak hesaplanmıştır. Yanma sonucu kül içeriği \%7,19, baca gazı emisyon değerleri sırası ile $\mathrm{CO} 1383.67 \mathrm{ppm}, \mathrm{CO}_{2}$ $\% 0,90, \mathrm{O}_{2} \% 19,17, \mathrm{NO} 121 \mathrm{ppm}, \mathrm{NO}_{\mathrm{x}} 61,67 \mathrm{ppm}$ olduğu görülmüştür [11].

Dağtekin ve arkadaşları (2019), limon budama atıklarından biyoyakıt amaçlı pelet elde etmişlerdir. Çalışmada peletlerin baca gaz emisyonları ve bazı fiziksel özellikleri belirlenmiştir. Peletlerin parça yoğunluğu $1236,70 \mathrm{~kg} / \mathrm{m}^{3}$, nem içeriği \%10, mekanik dayanıklılığ $\% 88$, sertliği $2951 \mathrm{~N}$ olarak bulunmuştur [12].

Atay ve Ekinci (2020), gül yağı işleme atıkları ile kızılçam ağaç kabuğu ve linyit kömür tozu kullanılarak pelet yapılması amaçlanmıştır. Daha sonrasında üretilen peletlerin fiziksel, kimyasal ve mekanik özelliklerinin belirlenmesi amaçlanmıştır. Öğütülmüş olan yă̆ gülü damıtma atıkları, kızılçam ağaç kabuğu ve linyit kömür tozundan altı farklı karışım elde edilmiş ve $3 \mathrm{~kW}$ motor gücüne sahip ve dairesel sıralı ve delikli düz kalıp peletleme makinesinde peletleme işlemi yapılmıştır. Peletlere yapılan fiziksel, kimyasal, mekanik ve termogravimetrik testlerinin sonucunda, pelet karışımlarında linyit kömür tozu arttıkça pelet parça yoğunluğunun da arttığ 1 gözlenmiştir. Ayrıca termogravimetrik analiz sonuçlarında linyit kömür tozunun fazla olduğu karışımların daha yavaş yandığı ancak yağ gülü damıtma atığının ve kızılçam ağaç kabuğunun fazla olduğu karışımların daha hızlı yandığı belirlenmiştir. Peletlerin kırılma ve sıkıştırma gibi dirençlerinin arttırılması için de peletleme işlemi sırasında buhar uygulaması yapılması gerektiği belirlenmiştir [9].

\section{MATERYAL VE METOT}

\subsection{Materyal}

Kahramanmaraş Sütçü İmam Üniversitesi Ziraat Fakültesi Biyosistem Mühendisliği Bölümü laboratuvarlarında yürütülen bu çalışmada, enerji amaçlı peletler için materyal olarak fabrikalardan

alınan pamuk çiğidi küspesi (Şekil 1) ve kırmızıbiber işleme atıkları (Şekil 2) kullanılmıştır. Pamuk çiğidi küspesi ve kırmızıbiber işleme atıkları kurutulmuş ve ardından sanayi tipi, elek çap1 $4 \mathrm{~mm}$ olan öğütücü yardımıyla öğütülme işlemine tabi tutulmuştur.

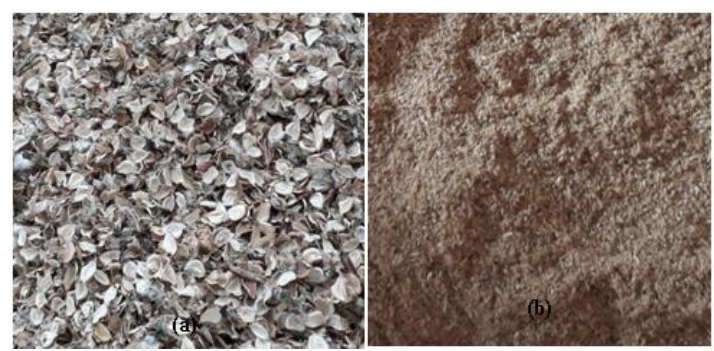

Şekil 1. Pamuk çiğidi küspesi (a) ve kurutulmuş hali (b)

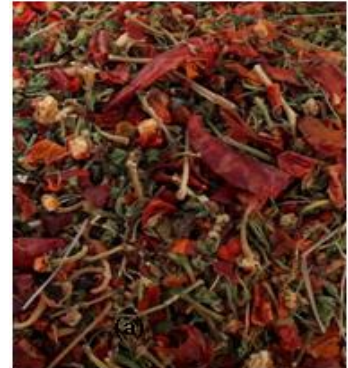

Şekil 2. Kırmızıbiber kurutulmus hali (b)

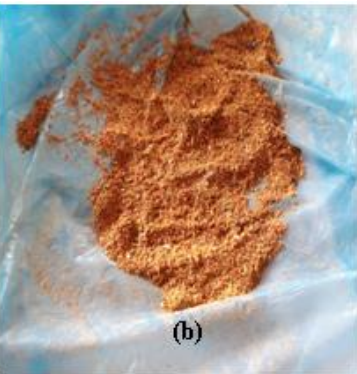

sleme atıkları (a) ve (b)

Kurutulup ögütülen materyaller, $6 \mathrm{~kW}$ motor gücüne sahip peletleme makinesinde peletlenmiştir. Peletleme makinesi dairesel sıralı delikli, boyut ayarlama düzeneğine sahip olup redüktör dönü sayısı $96 \mathrm{~d} / \mathrm{d}$ ve işleme kapasitesi 70-90 kg/h'dir (Şekil 3).

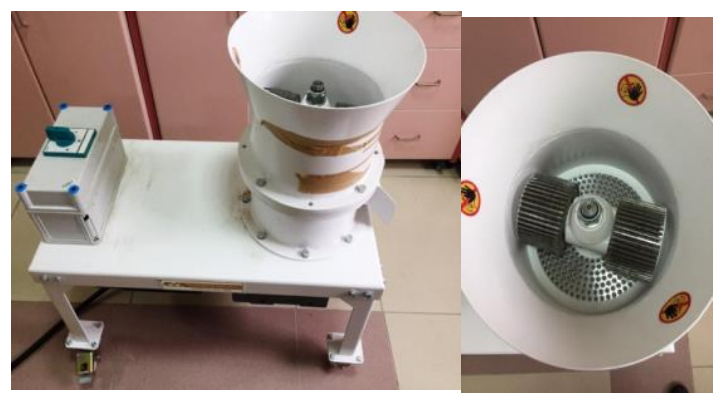

Şekil 3. Peletleme makinesi 
Çizelge 1. Pamuk çiğidi küspesi ve kırmızıbiber işleme atıklarından oluşan karışımlar

\begin{tabular}{|l|c|c|c|c|c|}
\hline Materyal & Karışım-1 & Karışım-2 & Karışım-3 & Karışım-4 & Karışım-5 \\
\hline PÇK & $\% 100$ & $\% 75$ & $\% 50$ & $\% 25$ & $\% 0$ \\
\hline KB & $\% 0$ & $\% 25$ & $\% 50$ & $\% 75$ & $\% 100$ \\
\hline
\end{tabular}

Peletleme işlemi için kırmızıbiber işleme atıkları (KB) ve pamuk çiğidi küspesinin (PÇK) farklı oranlarda karıştırılması ile 5 farklı karışım oluşturulmuştur (Çizelge 1).

Başlangıç nem oranı \%9 olan materyaller, peletleme işlemi için her bir karışım türü ayrı kaplara alınarak \%5 sivi melas ile homojen bir karışım oluşturulmuştur. Oluşturulan bu karışım bir kap yardımı ile peletleme makinesine dökülmüştür. Peletleme makinesinin deliklerinde kesit giderek daralmış ve sürekli pelet çıkışı (Şekil 4) meydana gelmiştir. Bu işlem her karışım türü için tekrar edilmiştir. Bir karışım türünden diğerine geçmeden önce peletleme makinesi ve delikleri temizlenmiştir.

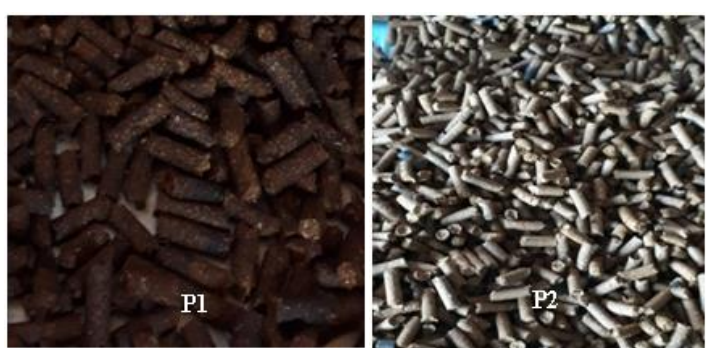

Şekil 4. Kullanılan materyallerden elde edilen pelet örnekleri

\subsection{Metot}

Pelet parça yoğunluğunun belirlenebilmesi için her karışım türünden elde edilen peletler içerisinden rastgele 40 adet seçilmiş ve her peletin çap, uzunluk ve kütle değerleri ölçülmüştür. Peletlerin çap ve uzunluk değerleri $0,01 \mathrm{~mm}$ hassasiyetine sahip dijital kumpas yardımıyla, kütleleri ise 0,001 hassasiyeti olan hassas terazide yapilan tartma işlemi sonucu belirlenmiştir. Pelet parça yoğunluğu değeri $\mathrm{kg} / \mathrm{m}^{3}$ cinsinden hesaplanmıștır. Peletlerin; kül içeriği analizi, TS ISO 1171 standardı esas alınarak [13], nem içeriği değeri ASTMD 3173 [14] standardına göre, uçucu madde içeriği analizi, TS ISO 562 [15] standardına göre, sabit karbon içeriği analizi, ASTMD 3172 standardına [16] göre, toplam karbon ve azot içeriği analizleri AOAC (1990) [17] yöntemine göre belirlenmiştir.

Pelet kırılma direncini belirlemek için, beş farklı karışımın her birinden rastgele 4 adet seçilmiştir. Seçilen bu peletlerin kütleleri ölçülüp kaydedilmiş ve yaklaşık 1,80 m yükseklikten 4 defa sert zemine bırakılmıștır. Daha sonra $3,15 \mathrm{~mm}$ delik çapına sahip elek üzerinde elenmiştir. Kütle ölçümü tekrar yapılmıştır. Test sonrası pelet ağırlığının, test öncesi pelet ağırlığına oranlanması ile kırılma direnci \% olarak hesaplanmıştır.

Peletlerin üst 1sıl değeri, Eşitlik 1 kullanılarak belirlenmiştir (Baley and Blankenhorn, 1984).

$\mathrm{HHV}=0,312 \mathrm{FC}+0,1534 \mathrm{VC}$

Burada;

$\mathrm{HHV}$ : Üst 1sıl değeri $(\mathrm{MJ} / \mathrm{kg})$

FC : Sabit karbon içeriği (\%)

VC : Uçucu madde içeriği (\%)

Dikey sıkıştırma direnci için her bir karışımdan rastgele 3 adet pelet seçilmiştir. Seçilen peletler tek tek sıkıştırma ünitesine yerleştirilmiş ve peletin kırılması gerçekleşene kadar sabit oranlarla artan sıkıştırma kuvveti uygulanmıştır. Kırılma gerçekleştiği anda sıkıştırma işlemi durdurulmuştur. Sıkıştırma direnci N olarak ölçülmüş ve hesaplanmasında Eşitlik 2 kullanılmıştır (Liu ve arkadaşları, 2014).

$\sigma \mathrm{X}=\frac{2 \mathrm{~F}}{\pi \mathrm{dl}}$

Burada:

$\sigma \mathrm{x}$ : Dikey sıkıştırma direnci $(\mathrm{N})$

$\mathrm{F}$ : Uygulanan maksimum kırılma kuvveti $(\mathrm{N})$

D : Pelet çapı (m)

1 : Pelet uzunluğu (m)'dur. 
$\mathrm{Bu}$ testte her bir karışım içinden rastgele seçilen beş adet pelet, etüvde, $105{ }^{\circ} \mathrm{C}$ sicaklıkta yaklaşık 24 saat bekletilmiş ve ilk kütleleri ölçülüp kaydedilmiştir. Daha sonra $27{ }^{\circ} \mathrm{C}$ sicaklıkta ve $\% 90$ nem içeriğine sahip olan iklimlendirme kabininde bekletilip son kütleleri ölçülüp kaydedilmiştir. Nem alma direnci, Eşitlik 3 yardımıyla \% olarak hesaplanmıştıır.

$\mathrm{Pa}=\frac{(\mathrm{mf}-\mathrm{mi})}{\mathrm{mi}} \times 100$

Burada;

$\mathrm{Pa} \quad$ : Nem alma direnci (\%)

mf : Peletlerin son kütlesi (g)

mi : Peletlerin ilk kütlesi (g)'dır.

Peletlere ait yanma özelliğinin belirlenmesi amacıyla termogravimetrik analizler yapılmıştır. Numunelerin termal analizleri azot atmosferinde alınmıştır. Toz haline getirilmiş numuneler seramik krozelere konularak 30-920 ${ }^{\circ} \mathrm{C}$ 'ye kadar $10{ }^{\circ} \mathrm{C} /$ dakika'lik 1 sitma oranında analizler yapılmıştır. Beş farklı karışımın her birinden alınan peletler için uygulanan termogravimetrik analizde anlı alınan veriler bilgisayara kaydedilmiştir. Analiz bittikten sonra diferansiyel termogravimetrik analiz (DTGA) ve termogravimetrik analiz (TGA) sonuçları grafik olarak verilmiştir. TGA ve DTGA eğrilerinin yardımıyla peletlere ait kütle kayıp oranları, başlangıç bozunma sıcaklığı, maksimum bozunma sıcaklığı ve final bozunma sıcaklığı belirlenmiştir. Araştırmada, tüm veriler 3 tekerrürlü olarak ölçülmüş ve ortalama değerler alınmıştır. Bulunan değerler şekil, çizelgelere aktarılarak ve istatistik analizi yapilarak (SPPS One way anova, Tukey testi) yorumlanmıștır.

\section{BULGULAR VE TARTIŞMA}

\subsection{Peletlerin Kimyasal, Fiziksel ve Mekanik Özellikleri}

Çalışmada ele alınan farklı oranlardaki peletlerin kimyasal ve 1sıl özellikleri Çizelge 2'de verilmiştir.
Elde edilen peletlerin kül içerikleri \%14,38$\% 19,99$ arasında bulunmuştur. Maksimum kül içeriği \%100 PÇK'da meydana gelirken karışımlarda PÇK oranı artıkça kül oranı artmıştır. Nem değerleri \%6,58 - \%9,59 arasında belirlenmiş olup minimum $(\% 6,58) \% 50 \mathrm{PÇK}+\% 50 \mathrm{~KB}$ karışımında, maksimum $(\% 9,59) \% 75 \mathrm{PÇK}+\% 25$ KB karışımında bulunmuştur. Uygun nem içeriği değerinin EN 14774-1 standardına göre [18] $\leq 10$ olması gerekmektedir. Bulunan nem içeriği değerlerinin EN 14774-1 standardına uygun olduğu tespit edilmiştir.

Sabit karbon değerleri \%13,57 - \%21,27 arasında değişmiştir. Maksimum \%100 KB'da olurken minimum ise \%100 PÇK'de belirlenmiştir. Karışımlarda KB oranı artıkça sabit karbonda artış görülmüştür. Atay ve Ekinci (2020), tarafindan yağ gülü damıtma atıkları (YGD), linyit kömür tozu (LKT) ve kızılçam ağaç kabuğu (KAK) ile yapmış olduğu araştırmada sabit karbon değerlerinin $\% 13,09$ - \%32,49 arasında olduğunu bildirmiştir. Sabit karbon değerleri yapılan bu çalışma ile benzer aralıkta bulunmuştur.

Uçucu madde içeriği \%54,74 - \%61,86 arasında değişmiştir. Minimum değer \% 100 PÇK'de olurken maksimum değer \%25 KB + \%75 PÇK karışımında meydana gelmiştir. Atay ve arkadaşları (2018) [19] tarafından yapılan çalışmada, LKT'nin \%75 oranında kullanıldığı karışımın uçucu madde içeriği değeri \%43.8, KAK'nin \%75 oranında olduğu karışımda ise uçucu madde içeriği \%68,5 olarak belirlenmiştir. Bulunan uçucu madde içeriği değerlerinin, Atay ve arkadaşları (2018) tarafindan bulunan değerler ile karşılaştırılabilir düzeyde olduğu saptanmıştır.

Oluşturulan 5 farklı karışımdaki peletlerin karbon, azot içerikleri ile üst 1sıl değerleri hesaplanmıştır. Elde edilen peletlerin azot içerikleri incelendiğinde en yüksek değer \%100 KB'da \%5,56 olarak bulunurken en düşük değer \%100 PÇK için \%3,80 olarak bulunmuştur. Karbon içeriği hesaplamalarında en yüksek değer \%100 KB'da $\% 41,7$ olurken en düşük değer $\% 25 \mathrm{~KB}+\% 75$ PÇK \%38,6 olarak bulunmştur. Hidrojen içerikleri incelendiğinde en yüksek değer \%7,10 ile $\% 100$ KB'dan oluşan pelet örneğinde bulunmuştur. En 
düşük değer ise $\% 6,14$ ile $\% 75$ PÇK $+\% 100$ KB'dan oluşan pelet örneğinde bulunmuştur.

Üst 1sıl değerlerinden yüksek değer $15,18 \mathrm{MJ} / \mathrm{kg}$ değeri ile $\% 50 \mathrm{~KB}+\% 50$ PÇK'da olurken minimum değeri ise $13,01 \mathrm{MJ} / \mathrm{kg}$ değeri ile $\% 100$ PÇK'da elde edilen pelet örneğinde hesaplanmıştır. Karışımda KB oranı arttıkça üst 1sıl değerleri artmıştır.

Çizelge 2. Farklı oranlardaki peletlerin kimyasal ve 1sıl özellikleri

\begin{tabular}{|c|c|c|c|c|c|}
\hline Pelet karışımları & $\begin{array}{c}\% 100 \\
\mathrm{~KB}\end{array}$ & $\begin{array}{l}\% 75 \mathrm{~KB}+ \\
\% 25 \text { PCCK }\end{array}$ & $\begin{array}{l}\% 50 \mathrm{~KB}+ \\
\% 50 \text { PCCK }\end{array}$ & $\begin{array}{l}\% 25 \mathrm{~KB}+ \\
\% 75 \text { PCCK }\end{array}$ & \%100 PÇK \\
\hline \multicolumn{6}{|l|}{ Analizler \% } \\
\hline Kül içeriği & 14,38 & 14,84 & 15,07 & 15,82 & 19,99 \\
\hline Nem içeriği & 6,79 & 8,28 & 6,58 & 9,59 & 7,66 \\
\hline Sabit karbon & 21,27 & 20,12 & 18,38 & 15,81 & 13,57 \\
\hline Uçucu madde & 54,74 & 57,26 & 58,07 & 61,86 & 57,20 \\
\hline $\mathrm{N}$ & 5,56 & 4,64 & 4,60 & 3,83 & 3,80 \\
\hline $\mathrm{C}$ & 41,71 & 38,15 & 41,63 & 38,62 & 41,70 \\
\hline $\mathrm{H}$ & 7,10 & 6,54 & 6,69 & 6,14 & 6,62 \\
\hline \multicolumn{6}{|l|}{ Enerji değeri (Mj/kg) } \\
\hline Üst 1s1l değeri & 15,18 & 14,52 & 14,45 & 14,42 & 13,01 \\
\hline
\end{tabular}

Farklı oranlardaki peletlere ait parça yoğunluğu değerleri ile çap, uzunluk ve kütle değerleri Çizelge 3'te verilmiştir.

Elde edilen peletlerin çapları 6,75-6,98 mm, uzunlukları 24,84-34,48 mm, kütleleri ise 0,91-1,44 g arasında olduğu tespit edilmiştir. Avrupa Pelet Konseyi tarafindan hazırlanan el kitabında belirtilen EN16127 [20] standardına göre en uygun pelet çapı 6-8 $\mathrm{mm}$ aralığında, pelet uzunluğu ise $3,15-40 \mathrm{~mm}$ olarak verilmiştir. Bulunan çap ve uzunluk değerlerinin EN16127 standardına uygun olduğu belirlenmiştir. Araştırma sonucunda pelet parça yoğunluğu değerleri 994,06$1177,51 \mathrm{~kg} / \mathrm{m}^{3}$ olarak belirlenmiştir. PÇK oranı artıkça pelet parça yoğunluğu artmıștır. Karışımlar arası pelet parça yoğunluklarında önemli düzeyde farklılık bulunmuştur $(\mathrm{P}<0,05)$. Atay ve arkadaşları (2018) [19] şeftali çekirdeği ve linyit kömür tozu kullanılarak üretilen peletlerin parça yoğunluğu değerlerinin $647-1059 \mathrm{~kg} / \mathrm{m}^{3}$ aralığında, Koçer ve arkadaşları (2018) [21] zeytin budama atıklarının peletleme yöntemi ile değerlendirilmesi çalışmasında parça yoğunluğu 981-1232 kg/m³ olarak belirlemişlerdir. Bulunan parça yoğunluğu değerlerinin Atay ve arkadaşları (2018) [19] ve Koçer ve arkadaşları (2018) [21] tarafından yapılan çalışmalardan elde edilen sonuçlarla benzer aralıkta olduğu söylenebilir.

Çizelge 3. Farklı oranlardaki peletlere ait parça yoğunluğu değerleri ile çap, uzunluk ve kütle değerleri

\begin{tabular}{|l|c|c|c|c|}
\hline Peletler & Çap (mm) & Kütle $(\mathbf{g})$ & Uzunluk (mm) & $\begin{array}{c}\text { Pelet parça yoğunluğu } \\
\left(\mathbf{k g} / \mathbf{m}^{\mathbf{3}}\right)\end{array}$ \\
\hline$\% 100 \mathrm{PÇK}$ & 6,72 & 1,44 & 34,48 & $1177,51 \mathrm{a}$ \\
\hline$\% 100 \mathrm{~KB}$ & 6,80 & 0,91 & 24,84 & $994,06 \mathrm{e}$ \\
\hline$\% 75 \mathrm{PÇK}+\% 25 \mathrm{~KB}$ & 6,75 & 1,38 & 26,32 & $1121,37 \mathrm{~b}$ \\
\hline$\% 50 \mathrm{PÇK}+\% 50 \mathrm{~KB}$ & 6,98 & 1,08 & 26,32 & $1072,35 \mathrm{c}$ \\
\hline$\% 25 \mathrm{PÇK}+\% 75 \mathrm{~KB}$ & 6,82 & 1,26 & 32,88 & $1049,01 \mathrm{~d}$ \\
\hline
\end{tabular}

Satır içerisinde aynı harfleri alan değerler arasında istatiksel olarak anlamlı bir fark yoktur $(P<0,05)$. 
Peletlerin dikey sıkıştırma direnci, kırılma direnci, nem alma oranı Çizelge 4'te verilmiştir.

Karışımlarda dikey sıkıştırma değerler 165,01319,82 N değerleri arasında bulunmuştur. Maksimum değer \%100 PÇK' de olurken minimum değer ise \%100 KB'da olmuştur. Karışımlarda PÇK oranı artıkça dikey sıkıştırma değeri artmıştır. Karışımlar arası dikey sıkıştırma direncinde önemli düzeyde farklılık bulunmuştur $(\mathrm{P}<0,05)$. Peletlerin dikey sıkıştırılması ile yapılan araştırmalarda; Garsia- Maraver ve arkadaşları 2010 [22] Zeytin dalı ve yapraklarından elde edilen peletlere uygulamasinda 40-220 N, Celma ve arkadaşları (2010) [23] domates posası peletleri için yapmış araştırmaında en yüksek $88 \mathrm{~N}$ olarak belirlemiştir. Hesaplanan sıkıştırma direnci Celma ve ark. tarafindan bulunan sonuçtan yüksek, Garsia-Maraver ve arkadaşları 2010 tarafından bulunan sonuç ile yakın olduğu saptanmıştır. $\mathrm{Bu}$ çalışma ile farklılığın olmasının nedeni materyallerdeki fiziksel ve kimyasal yapılarının farklı olmasından kaynaklanabilir.

Peletlerin kırılma direnci değerleri \%99,04-\%99,71 aralığında bulunmuştur. Maksimum kırılma direnci $\% 50 \quad \mathrm{PÇK}+\% 50 \quad \mathrm{~KB}$ 'da olurken, minimum ise \%100 PÇK'de meydana gelmiştir. Karışımlar arası kırılma direncinde önemli düzeyde farklılık bulunmamıştır $(\mathrm{P}<0,05)$. Kırılma direnci değerleri ile yapılan çalışmalarda; Yılmaz, (2014) [10] tarımsal atıkların peletlenmesi ve peletlerin fiziksel özelliklerinin belirlenmesindeki kırılma direncini \%99,26-\%99,99, Bilgin ve arkadaşları (2015) [24] findik zurufunun peletlenmesi ve pelet fiziksel özelliklerinin belirlenmesi üzerine yaptı̆̆ araştırmada pelet kırılma direncini \%99,60 olarak belirlemiştir. Yapılan bu çalışma literatür ile karşılaştırıldığında elde edilen değerler benzer aralıkta olduğu tespit edilmiştir.

Peletlerin taşınma veya depolama süreci boyunca nemin yoğun olduğu ortamlarda bulundurulması peletlerin kalitesini ve dayanımını olumsuz yönde etkilemektedir [25]. Yüksek miktarda neme maruz kalan peletler kolayca kırılmakta ve toz oluşmaktadır. Bu gibi durumlarla karşılaşılmaması için peletler için uygun nem koşulunda taşıma veya depolanması sağlanmalıdır. Elde edilen 5 farklı karışımdan nem alma oranı $\% 20,06$ - \%23,55 değerleri arasısında bulunmuştur. Maksimum nem alma oranı \%100 KB'da olurken minimum ise \%100 PÇK'de meydana gelmiştir. Karışımlarda KB oranı artıkça nem alma oranında artma oluşmuştur. Karışımlar arası nem alma oranında önemli düzeyde farklılık bulunmuştur $(\mathrm{P}<0,05)$. Peletlerinin nem alma oranı ile yapılan diğer çalışmalarda; Alparslan ve arkadaşları (2018) [26] karanfil bitkisine ait biyokütle atıklarının peletlenmesinde parça boyutunun etkisinin araştırmasında nem alma oranını \%18-\%20 aralığında, Yılmaz, (2018) [27] mısır saplarının peletlenmesi çalışmasında nem alma oranını $\% 11,53$ olarak belirlemişlerdir. $\mathrm{Bu}$ durumda bulunan nem alma dirençleri Alparslan ve arkadaşları (2018) tarafindan yürütülen çalışmada bulunan değere yakın, Y1lmaz, (2018) [22] tarafından yapılan çalışmada hesaplanan değerden ise yüksek olduğu tespit edilmiştir. Bu farklılığın olması materyallerin farklı olmasından kaynaklanabilir.

Çizelge 4. Farklı oranlardaki peletlerin dikey sıkıştırma direnci, kırılma direnci, nem alma oranı

\begin{tabular}{|l|c|c|c|}
\hline Peletler & Dikey sıkıştırma direnci (\%) & Kırılma direnci (\%) & Nem alma oranı (\%) \\
\hline \%100 PÇK & $319,82 \mathrm{a}$ & $99,04 \mathrm{a}$ & $20,06 \mathrm{e}$ \\
\hline \%75PÇK+\%25KB & $275,41 \mathrm{~b}$ & $99,55 \mathrm{a}$ & $20,55 \mathrm{~d}$ \\
\hline \%50PÇK+\%50KB & $209,41 \mathrm{c}$ & $99,71 \mathrm{a}$ & $21,43 \mathrm{c}$ \\
\hline \%25PÇK+\%75KB & $183,61 \mathrm{~d}$ & $99,55 \mathrm{a}$ & $21,99 \mathrm{~b}$ \\
\hline$\% 100 \mathrm{~KB}$ & $165,01 \mathrm{e}$ & $99,15 \mathrm{a}$ & $23,25 \mathrm{a}$ \\
\hline
\end{tabular}

Satır içerisinde aynı harfleri alan değerler arasında istatiksel olarak anlamlı bir fark yoktur $(P<0,05)$. 


\subsection{Peletlere Uygulanan Termogravimetrik Analizler}

Peletlerin yanma karakteristiklerinin belirlenmesinde kullanılan en iyi yöntemlerden bir tanesi termogravimetrik analiz (TGA) yöntemidir. Diferansiyel termogravimetrik analiz (DTGA) ise kimyasal tepkimenin sonucunda ortaya çıkan enerji değişimini belirlemek için kullanılan bir yöntemdir [9]. Farklı oranlarda KB ve PÇK içeren peletlerin, $30-1000{ }^{\circ} \mathrm{C}$ sicaklık aralığında ve $10{ }^{\circ} \mathrm{C} /$ dak. artış hızı neticesinde oluşan tüm karışım türlerine ait peletlerin TGA bozunma eğrilerine Şekil 5'de, tüm karışım türlerine ait peletlerin DTGA bozunma eğrilerine ise Şekil 6'da yer verilmiştir. Ayrıca Çizelge 5'de başlangıç bozunma sıcaklığı $\left(\mathrm{T}_{\mathrm{i}}\right)$, maksimum bozunma sıcaklığı $\left(\mathrm{T}_{\max }\right)$ ve final bozunma sicaklığı $\left(\mathrm{T}_{\mathrm{f}}\right)$ verilmiştir.

Pelet örneklerinin TG eğrilerinde önemli ölçüde 2 kütle kaybının meydana geldiği tespit edilmiştir. İlk kütle kayb1 $100{ }^{\circ} \mathrm{C}$ sicaklıkta suyun buharlaşması ile gerçekleşmiş olmakla birlikte maksimum su kütlesi kaybı, yaklaşık \%9 ile \%100 PÇK'dan oluşan pelet örneğinde gerçekleşmiştir. $\mathrm{Bu}$ değer \%100 KB'dan oluşan pelet için yaklaşık $\%$, diğer karışım oranlarından oluşan peletler için yaklaşık \%8 olarak hesaplanmıştır. Elde edilen peletlerin $900^{\circ} \mathrm{C}$ 'de maksimum kütle kayıplarının sırası ile \%75 PÇK+\%25 KB için \%77,8, \%100 PÇK için \%78, \%100 KB için \%79,6, \%50 $\mathrm{KB}+\% 50$ PÇK için \%80,9 ve \%75 KB + \%25 PÇK için \%83,1 olduğu belirlenmiştir (Şekil 5-6).

İlk bozunma sicaklıkları \%100 KB'dan oluşan pelet için $152{ }^{\circ} \mathrm{C}, \% 100 \mathrm{PÇK}$ 'dan oluşan pelet için $158^{\circ} \mathrm{C}, \% 75 \mathrm{PÇK}+\% 25 \mathrm{~KB}$ 'dan oluşan pelet için $118^{\circ} \mathrm{C}, \% 75 \mathrm{~KB}+\% 25 \mathrm{PÇK}$ 'dan oluşan pelet için $121{ }^{\circ} \mathrm{C}$ ve $\% 50 \mathrm{~KB}+\% 50$ PÇK' dan oluşan pelet için $143{ }^{\circ} \mathrm{C}$ 'de gerçekleşmiştir (Şekil 5-6, Çizelge 5).

Maksimum bozunma sicaklıkları \%100 KB'dan oluşan pelet için $323^{\circ} \mathrm{C}, \% 100$ PÇK'dan oluşan pelet için $310^{\circ} \mathrm{C}, \% 75 \mathrm{PÇK}+\% 25 \mathrm{~KB}$ 'dan oluşan pelet için $325^{\circ} \mathrm{C}, \% 75 \mathrm{~KB}+\% 25 \mathrm{PÇK}$ 'dan oluşan pelet için $315{ }^{\circ} \mathrm{C}$ ve $\% 50 \mathrm{~KB}+\% 50$ PÇK'dan oluşan pelet için $305{ }^{\circ} \mathrm{C}$ gerçekleştiği tespit edilmiştir (Şekil 5-6, Çizelge 5).

Elde edilen peletlerde final bozunma sicaklıkları, $\% 100 \mathrm{~KB}$ 'dan oluşturulan pelet için $554{ }^{\circ} \mathrm{C}, \% 100$ PÇK'dan oluşturulan pelet için $500{ }^{\circ} \mathrm{C}$, \%75 $\mathrm{PÇK}+\% 25 \mathrm{~KB}$ 'dan oluşturulan pelet için $461{ }^{\circ} \mathrm{C}$, $\% 75 \mathrm{~KB}+\% 25$ PÇK karışımından oluşturulan pelet için $510{ }^{\circ} \mathrm{C}$ ve $\% 50 \mathrm{~KB}+\% 50$ PÇK karışımından oluşturulan pelet için $517{ }^{\circ} \mathrm{C}$ olarak hesaplanmıştır (Şekil 5-6, Çizelge 5).

İkinci kütle kayıp oranları ie 3,5-5,5\%/dk arasında değişmiştir. Numunelerin minimum kütle kayıp oranının $\% 100 \mathrm{~KB}$ 'da 3,5\%/dk, maksimum kütle kayıp oranı ise \%100 PÇK'da 5,5\%/dk olarak bulunmuştur (Şekil 5-6, Çizelge 5). Karışımlar arası kütle kayıp oranında önemli düzeyde farklılık bulunmuştur $(\mathrm{P}<0,05)$. Atay ve Ekinci (2020) tarafindan yapılan çalışmada ikinci kütle kayıp oranları 1,43 ile 2,83 \%dk aralığında bulunmuştur ve PÇK ve KB karışımları kullanılarak yapılan çalışmada ki ikinci kütle kayıp oranları ile karşılaştırıdığında bulunan değerlerin Atay ve Ekinci (2020) [9] tarafından yapılan çalışmada bulunan değerlerden yüksek olduğu sonucuna varılmıştır.

Yapılan analizler neticesinde pamuk çiğidi küspesi atıklarının yoğunlukta olduğu peletlerde yanma işlemi daha itidalli şekilde gerçekleşmiştir.

Kırmızıbiber işleme atıklarının yoğunlukta olduğu peletlerde yanma işlemi daha hızlı şekilde gerçekleşmiştir. Wang (2008) [28] tarafından yapılan çalışmada kütle kayıp oranının düşük ve son tepe sıcaklığının yüksek olduğu durumlarda yanma işleminin daha mutedil gerçekleştiği belirtilmiştir. Buna göre, karışımlarda PÇK'nin yoğunluğunun arttırılmasıla yanma kalitesi artacağı söylenebilir. 


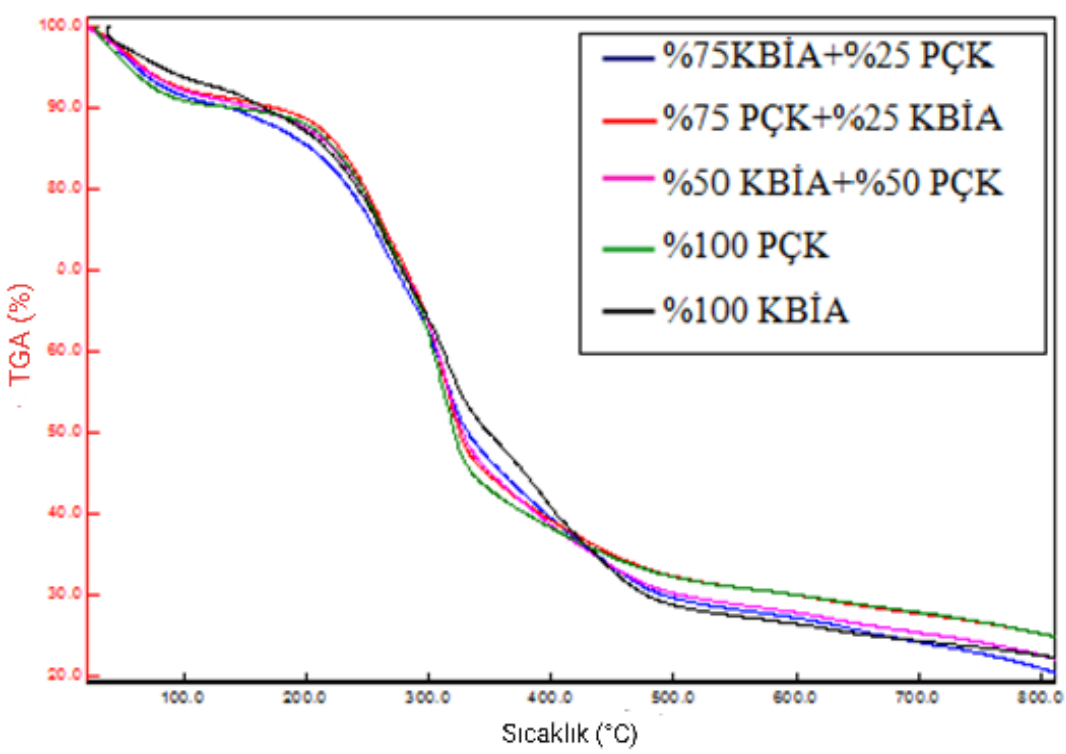

Şekil 5. Tüm peletlerin TGA eğrileri

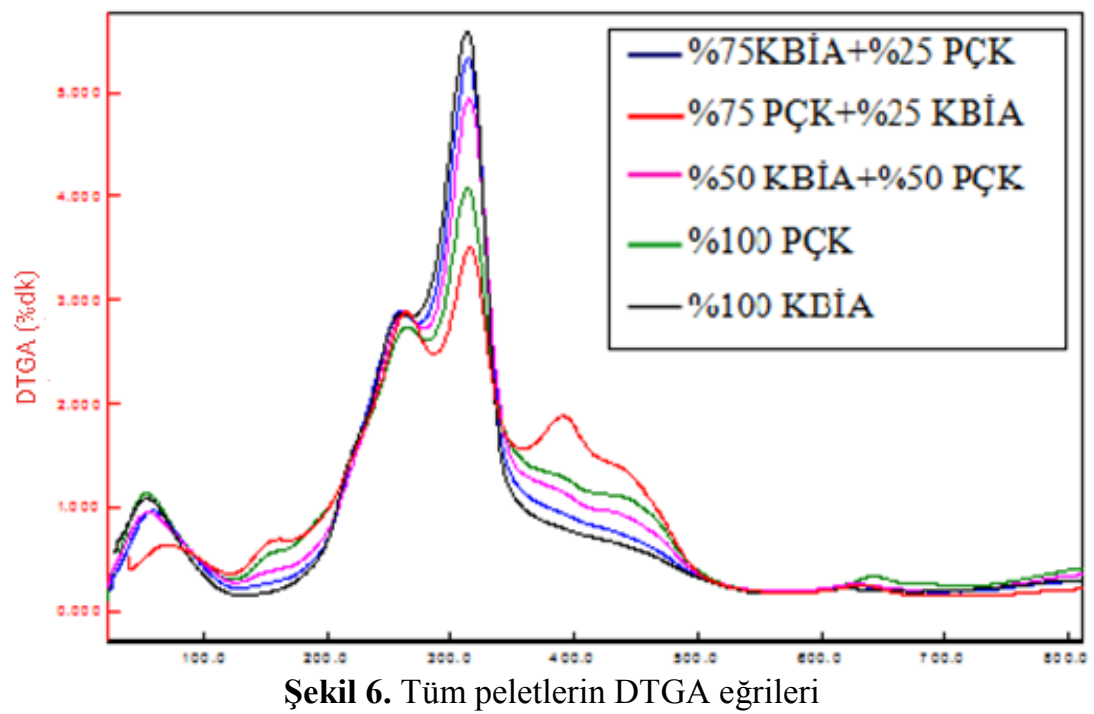

Çizelge 5. Kullanılan peletlerin başlangıç bozunma, maksimum bozunma ve final bozunma sıcaklığı ile maksimum kütle kayıp oranları

\begin{tabular}{|l|c|c|c|c|}
\hline Peletler & $\mathbf{T}_{\mathbf{i}}\left({ }^{\circ} \mathbf{C}\right)$ & $\mathbf{T}_{\max }\left({ }^{\circ} \mathbf{C}\right)$ & $\mathbf{T}_{\mathbf{f}}\left({ }^{\circ} \mathbf{C}\right)$ & Maksimum kütle kayıp oranı (\%/dk) \\
\hline$\% 100 \mathrm{~KB}$ & 152 & 323 & 554 & $3,5 \mathrm{~d}$ \\
\hline$\% 100 \mathrm{PÇK}$ & 158 & 310 & 500 & $5,5 \mathrm{a}$ \\
\hline$\% 75 \mathrm{PÇK+ \% 25KB}$ & 118 & 325 & 461 & $5,2 \mathrm{~b}$ \\
\hline$\% 75 \mathrm{~KB}+\% 25 \mathrm{PÇK}$ & 121 & 315 & 510 & $4,2 \mathrm{c}$ \\
\hline$\% 50 \mathrm{~KB}+\% 50 \mathrm{PÇK}$ & 143 & 305 & 517 & $5,1 \mathrm{~b}$ \\
\hline
\end{tabular}

Satır içerisinde aynı harfleri alan değerler arasında istatiksel olarak anlamlı bir fark yoktur $(P<0,05)$. 


\section{SONUÇLAR VE ÖNERILER}

Farklı oranlarda karıştıran peletlerde yapılan ölçüm ve değerlendirmelerden elde edilen sonuçlar aşağıda sıralanmıştır.

- Peletlerin kütle, uzunluk ve çap ölçümleri yapılmış ve bu sonuçların Avrupa Pelet Konseyi'nce belirlenen standartlara uygun olduğu tespit edilmiştir.

- Karışımlarda PÇK oranı artıkça kül oranı artmıştır.

- Bulunan nem içeriği değerlerinin EN 4774-1 standardına uygun olduğu tespit edilmiştir.

- PÇK oranı artıkça pelet parça yoğunluğu artmıştır.

- Karışımlarda PÇK oranı artıkça dikey sıkıştırma değeri artmıştır

- Karışımlarda KB oranı artıkça nem alma oranında artma oluşmuştur.

- Karışımlarda kütle kayıp oranlarında PÇK oranı artıkça artma gözlemlenmiştir

- Yapilan termogravimetrik analizler ve diferansiyel termogravimetrik analizler eticesi pamuk çiğidi küspesinin yoğunlukta olduğu peletlerde yanma işleminin daha itidalli şekilde gerçekleşmiştir. Ancak kırmızıbiber işleme atıklarının yoğunlukta olduğu peletlerde ise yanma işleminin daha hızlı gerçekleştiği saptanmıştır.

- \%100 PÇK'den üretilen peletler; termogravimetrik analizler, nem alma oranı hesaplamaları, dikey sıkıştırma analizi hesaplamaları neticesinde incelenmiş ve kullanım için uygun olacağı sonucuna varılmıştır.

Bu çalışma ile ilgili şu önerilerde bulunulabilir.

- Kırmızıbiber ve pamuk çiğidi küspesi işleme atılarının peletlenerek yakıt olarak kullanılması verimlilikleri arttırabilirir.

- Kırmızıbiber işleme atıkları ve pamuk çiğidi küspesi pelet üretimi için uygun materyallerdir.

- Pelet üretiminde tarımsal atıkların kullanılması ile çevre kirliliği azaltılabilir.

- Türkiye'de kırmızıbiber ve pamuk üretiminin önemli düzeyde olmasından dolayı pelet üretiminde bu materyallerden elde edilecek atıklar kullanılabilir.

- Türkiye'de yetişen diğer tarım ürünlerini pelet üretimi konusunda denemek, elde edilecek enerjinin üretim oranlarını belirlemek veritabanının güçlenmesine katkı sağlayabilir.

- Gelecekte yapılacak çalışmalarda üretilen peletler, nem içeriğinin yüksek olduğu ortamlarda muhafaza edilmemelidir. Eğer muhafaza edilir ise bu durum kütle artışına sebep olabilecek ve pelet kalitesi olumsuz etkilenebilecektir.

\section{KAYNAKLAR}

1. Şenpınar, A., Gençoğlu, M.T., 2006. Yenilenebilir Enerji Kaynaklarının Çevresel Etkileri Açısından Karşılaştırılması. Doğu Anadolu Bölgesi Araştırma Dergisi, 4(2), 49-54.

2. Aybek, A., Üçok, S., 2017. Determination and Evaluation of Biogas and Methane Productions of Vegetable and Fruit Wastes with Hohenheim Batch Test Method. International Journal of Agricultural and Biological Engineering, 10(4), 207-215.

3. Kurtuluş, E., 2004. Yüksek Pirinanın Bir Yakıt Olarak Kullanımı ve Eldesi. Ege Üniversitesi, Mühendislik Fakültesi, Makine Mühendisliği Bölümü, İzmir.

4. Karkania, V., Fanara, E., Zabaniotou, A., 2012. Review of Sustainable Biomass Pellets Production-A Study for Agricultural Residues Pellets' Market in Greece. Renewable and Sustainable Energy Reviews, 16(3), 1426-1436.

5. Küsek, G., Güngör, C., Öztürk, H., Akdemir, S., 2015. Tarımsal Atıklardan Biyopelet Üretimi. Uludağ Üniversitesi, Ziraat Fakültesi Dergisi (Journal of Agricultural Faculty of Uludag University), 29(2), 137-145.

6. Aydemir, T., 2017. Farklı Tarımsal Artıklar Kullanılarak Karışım Peletlerinde Kenevir Sapı Kullanımının Pelet Kalite Özellikleri Üzerine Etkisi. Yüksek Lisans Tezi, Namık Kemal Üniversitesi, Fen Bilimleri Enstitüsü, Tekirdağ. 79.

7. Küsek, G., Güngör, C., Öztürk, H., Akdemir, Ş., 2015. Tarımsal Atıklardan Biyopelet 
Üretimi. Uludağ Üniversitesi Ziraat Fakültesi Dergisi (Journal of Agricultural Faculty of Uludag University) 29 (2), 137-145.

8. Bilgin, S., Koçer, A., Yılmaz, H., Acar, M., Dok, M., 2016. Çay Fabrikası Atıklarının Peletlenmesi ve Pelet Fiziksel Özelliklerinin Belirlenmesi, Gaziosmanpaşa Üniversitesi Ziraat Fakültesi Dergisi, 33 (Ek say1),70-80.

9. Atay, O. A., Ekinci, K. 2020. Characterization of Pellets Made from Rose Oil Processing Solid Wastes/coal Ppowder/pine Bark. Renewable Energy, 149, 933-939.

10. Yılmaz, H., 2014. Bazı Tarımsal Atıkların Peletlenmesi ve Pelet Fiziksel Özelliklerinin Belirlenmesi Üzerine Bir Araştırma. Yüksek Lisans Tezi, Akdeniz Üniversitesi, Fen Bilimleri Enstitüsü, Tarım Makinaları ve Teknolojileri Mühendisliği, Antalya.

11. Gürdil, G.A.K., Baz, Y.Ö., Dok, M., Acar, M., Demirel, Ç., 2016. Fındık Zurufundan Üretilen Yakıt Peletinin Isısal Parametreleri. 2. Ulusal Biyo-Yakitlar Sempozyumu, 27-30.

12. Dağtekin, M., Gürdil, G., Demirel, B., 2019. Bio-energy Potential from Lemon Orchards. $7^{\text {th }}$ TAE 17-20 September Prague, Czech Republic.

13. TS ISO-1171, 2014. Tüm Katı Mineral Yakıtların Kül Miktarının Tayini Yöntemi, Türk Standartları Enstitüsü, Ankara.

14. ASTM-D3173, 2013. Nem İçeriği Tayin Methodu. American Society for Testing Materials, ABD.

15. TS 711 ISO-562, 2002. Uçucu Maddenin Tayin Methodu, Türk Standartları Enstitüsü, Ankara.

16. ASTM-D3172, 1990. Sabit Karbon İçeriği Tayin Yöntemi. American Society for Testing Materials, ABD.

17. AOAC, 1990. Official Methods of Analysis. $15^{\text {th }}$ ed. Association of Official Analytical Chemists, Washington, DC. US.

18. EN 14774-1, 2009. Solid Biofuels. Determination of Moisture Content. Oven Dry Method. Total Moisture. British Standards Institution, London.

19. Atay, O., Ekinci, K., Kaçar, H., Üçok, S., Kumbul, B.S., Aybek, A., 2018. Şeftali Çekirdeği ve Linyit Kömür Tozundan Yapılan Peletlerin Fiziko Mekanik Özellikleri, 1.
Uluslararası Tarımsal Yapılar ve Sulama Kongresi Özel Sayıs1: 274-280.

20. EN 16127, 2012 Solid Biofuels-Determination of Length and Diameter of Pellets; European Committee for Standardization: Brussels, Belgium.

21. Koçer, A., Kürklü, A., 2018. Zeytin Budama Atıklarının Budama İle Değerlendirilmesi, Tarım Makinaları Bilim Dergisi (Journal of Agricultural Machinery Science), 14(2), 67-72.

22. Garcia-Maraver, A., A.F Ramos-Ridao, D.P. Ru1z, Zamorano, M., 2010. Quality of Pellets from Olive Grove Residual Biomass. International Conference on Renewable Energies and Power Quality (ICREPQ'10), Granada-Spain.

23. Celma, A.R., Cuadros, F., Rodriguez, F.L., 2012. Characterization of Pellets for Industrial Tomato Residues, Food and Bio products Processing, 90, 700-706.

24. Bilgin, S., Yılmaz, H., Koçer, A., Acar, M., Dok, M., 2015. Findık Zurufunun Peletlenmesi ve Pelet Fiziksel Özelliklerinin Belirlenmesi, Tarım Makineleri Bilim Dergisi (Journal of Agricultural Machinery Science), 11(3), 265-273.

25. Kaliyan, N., Morey, R.V., 2009. Factor Affecting Strength and Durability of Densified Biomass Products. Biomass and Bioenergy, 33, 337-359.

26. Alparslan, S., Ertekin, C., 2018. Karanfil Bitkisi Biyokütle Atıklarının Peletlenmesinde Parça Boyutunun Etkisi. Tarım Makineleri Bilim Dergisi (Journal of Agricultural Machinery Science), 14(1), 7-13.

27. Yılmaz, H., 2018. Misir Saplarının Peletlenmesi ve Pelet Özelliklerinin Belirlenmesi. Mediternian Agricultural Sciences, 31(3), 269-274.

28. Wang, C., Wang, F., Yang, Q., Liang, R., 2008. Thermogravimetric Studies of the Behavior of Wheat Straw with Added Coal During Combustion. College of Mechanical \& Electronic Engineering, Qingdao University, 266071, China, B I Biomass and Bioenergy, $33,50-56$. 